University of Wollongong

Research Online

Australian Institute for Innovative Materials -

Papers

Australian Institute for Innovative Materials

$1-1-2018$

\title{
Ultrathin and Edge-Enriched Holey Nitride Nanosheets as Bifunctional Electrocatalysts for the Oxygen and Hydrogen Evolution Reactions
}

\author{
Haipeng Guo \\ University of Wollongong, hg476@uowmail.edu.au \\ Boyang Ruan \\ University of Wollongong, boyang@uow.edu.au \\ Wenbin Luo \\ University of Wollongong, luow@uow.edu.au \\ Jianqiu Deng \\ Laboratory of Information Materials, Guilin University of Electronic Technology, jianqiu@uow.edu.au \\ Jiazhao Wang \\ University of Wollongong, jiazhao@uow.edu.au
}

See next page for additional authors

Follow this and additional works at: https://ro.uow.edu.au/aiimpapers

Part of the Engineering Commons, and the Physical Sciences and Mathematics Commons

Research Online is the open access institutional repository for the University of Wollongong. For further information contact the UOW Library: research-pubs@uow.edu.au 


\title{
Ultrathin and Edge-Enriched Holey Nitride Nanosheets as Bifunctional Electrocatalysts for the Oxygen and Hydrogen Evolution Reactions
}

\author{
Abstract \\ Exploring economically efficient electrocatalysts with good electrocatalytic activity is essential for diverse \\ electrochemical energy devices. Series of ultrathin metallic nickel-based holey nitride nanosheets were \\ designed as bifunctional catalysts for the oxygen evolution reaction (OER) and hydrogen evolution \\ reaction (HER). They exhibit improved catalytic properties owing to the inherent advantages of their \\ plentiful active reaction sites resulting from the complete exposure of the atoms in the large lateral \\ surfaces and from the edges of pore areas, together with expanded lattice spacing distance. This \\ obtained three-dimensional conductive integral architecture can not only accelerate the electron \\ transportation by the highly orientated crystalline structure but also facilitate the diffusion of intermediate \\ and gases. In terms of the OER electrocatalytic properties, a quite low overpotential $(300 \mathrm{mV})$ is required \\ for the holey two-dimensional (2D) Ni3Fe nitride nanosheets to deliver a current density of about $100 \mathrm{~A}$ \\ $\mathrm{g}-1$, with an enhanced improvement over IrO2by a factor of nearly 25 times. The holey 2D Ni3Fe nitride \\ nanosheets also exhibit enhanced catalytic performance toward the HER, with a tiny overpotential (233 \\ $\mathrm{mV}$ ) to achieve a current density of about $100 \mathrm{~A} \mathrm{~g}$ - 1 with much better kinetic properties in comparison to \\ those of highly active $\mathrm{Pt} / \mathrm{C}$.

\section{Disciplines} \\ Engineering | Physical Sciences and Mathematics

\section{Publication Details} \\ Guo, H., Ruan, B., Luo, W., Deng, J., Wang, J., Liu, H. \& Dou, S. (2018). Ultrathin and Edge-Enriched Holey \\ Nitride Nanosheets as Bifunctional Electrocatalysts for the Oxygen and Hydrogen Evolution Reactions. \\ ACS Catalysis, 8 (10), 9686-9696.
}

\section{Authors}

Haipeng Guo, Boyang Ruan, Wenbin Luo, Jianqiu Deng, Jiazhao Wang, Hua-Kun Liu, and Shi Xue Dou 


\section{Ultrathin and Edge-Enriched Holey Nitride}

\section{Nanosheets as Bifunctional Electrocatalysts for the}

\section{Oxygen and Hydrogen Evolution Reactions}

Hai-Peng Guo , Bo-Yang Ruan ${ }^{\dagger}$, Wen-Bin Luo ${ }^{*}$, Jianqiu Deng*, Jia-Zhao Wang *广, Hua-Kun Liu $^{\dagger}$, Shi-Xue Dou ${ }^{\dagger}$

${ }^{\dagger}$ Institute for Superconducting and Electronic Materials, University of Wollongong, Squires Way, Fairy Meadow, NSW 2500, Australia

$\$$ School of Material Science and Engineering \& Guangxi Key Laboratory of Information Materials, Guilin University of Electronic Technology, Guangxi, Guilin 541004, China

ABSTRACT: Exploring economically efficient electrocatalysts with good electrocatalytic activity is essential for diverse electrochemical energy devices. Series of ultrathin metallic nickel-based holey nitride nanosheets were designed as bifunctional catalysts for the oxygen evolution reaction (OER) and hydrogen evolution reaction (HER). They exhibit improved catalytic properties owing to the inherent advantages of their plentiful active reaction sites resulting from the complete exposure of the atoms in the large lateral surfaces and from the edges of pore areas, together with expanded lattice spacing distance. This obtained three-dimensional conductive integral 
architecture can not only accelerate the electron transportation by the highly orientated crystalline structure, but also facilitate the diffusion of intermediate and gases. In terms of the OER electrocatalytic property, a quite low overpotential $(300 \mathrm{mV})$ is required for the holey twodimensional (2D) $\mathrm{Ni}_{3} \mathrm{Fe}$ nitride nanosheets to deliver a current density about $100 \mathrm{~A} \mathrm{~g}^{-1}$, with an enhanced improvement than $\mathrm{IrO}_{2}$ by a factor of nearly 25 times. The holey $2 \mathrm{D} \mathrm{Ni} 3 \mathrm{Fe}$ nitride nanosheets also exhibit enhanced catalytic performance towards the HER, with a tiny overpotential $(233 \mathrm{mV})$ to achieve the current density about $100 \mathrm{~A} \mathrm{~g}^{-1}$ and much better kinetic property than those of highly-active $\mathrm{Pt} / \mathrm{C}$.

Keywords: Two-dimensional; Nitride electrocatalyst; LDH; Oxygen evolution reaction; Hydrogen evolution reaction

\section{INTRODUCTION}

Ultrathin two-dimensional (2D) holey nanostructures have drawn significant research attention for energy storage, catalysis, electronics, and biomedical science because their unique feature could provide unprecedented chemical, electronic, and physical properties resulting from the electron confinement in two dimensions. ${ }^{1-6}$ Due to their huge lateral surface area and atomic thickness, this special feature allows for direct correlation between the properties and the structure, giving superior atomic transport. They are frequently used as a bridge between microscale and

nanoscale features to realize the fabrication of future microscale devices. ${ }^{7-11}$ In contrast to the intact lateral surface, the holes on the lateral surface will result in ultrahigh specific surface area and a continuously connected integrated network, while maintaining atomic thickness, because the reaction intermediates can easily be transferred and diffuse throughout the whole porous system, not only along the large lateral surface direction, but also through holes on the surface, which can be considered as channels among numerous nanosheets. ${ }^{12-18} 2 \mathrm{D}$ holey nanosheets have inherent 
advantages for surface-related applications such as catalysis. For example, owing to the complete exposure of the large lateral surface atoms and the much greater number of catalytic active atoms in the hole area, it will dramatically accelerate the reaction kinetics, which would be much more favorable for achieving outstanding electrocatalytic performance towards the oxygen evolution reaction (OER) and hydrogen evolution reaction (HER). ${ }^{8,19}$ Meanwhile, this ultrathin holey 2D structure also presents excellent properties through accelerating the diffusion of the evaluated gases and electrolyte accessibility. ${ }^{2,20}$ Moreover, because of the excellent mechanical strength from the strong in-plane covalent bonds, this $2 \mathrm{D}$ porous nanostructured catalyst can also alleviate or even solve many of physical issues regarding state-of-the-art nanoparticle catalysts, such as aggregation or peeling off during the reaction, resulting in significant descent of the electrocatalytic performance. ${ }^{7,21-26}$ A number of 2D structured materials are employed as catalysts to facilitate the sluggish evolution reaction kinetics, for example precious metals, metal hydroxides/oxides, and metal sulfides. ${ }^{22,27-38}$ Among these, transition metal nitrides have the inherent advantages of high catalytic activity, economic efficiency, and superior electrical conductivity due to the introduction of nitrogen atoms into the metal hosts, which exhibit a metallic state with continuous conductivity near the Fermi level according to the computer calculations. ${ }^{32}$, 39-43 Therefore, in this work, a strategy is proposed to develop ultrathin 2D holey structured bimetallic nitride materials with a strong high-orientation crystalline texture. A series of ultrathin 2D holey nickel-based nitrides ( $\mathrm{Ni}_{3} \mathrm{M}$ nitride, $\left.\mathrm{M}=\mathrm{Fe}, \mathrm{Co}, \mathrm{Mn}\right)$ has been designed and successfully synthesized, with a satisfactory specific surface area $\left(189.6 \mathrm{~m}^{2} \mathrm{~g}^{-1}\right)$, maintaining $0.6-0.8 \mathrm{~nm}$ nanosheet thickness. The hierarchical porous continuously conductive architecture caused by the holey nitride nanosheets is much more beneficial to transport of reaction intermediates and gas diffusion throughout the entire electrode. The faster electron transportation along the ultrathin $2 \mathrm{D}$ 
direction can be further enhanced by their nearly single-crystalline structure, while the superior electrocatalytic performance could be ascribed to the highly exposed atoms on the large lateral surfaces, resulting from the vast surface area and plentiful exposed catalytically active atoms or lattice planes in the hole area. Furthermore, the influence of lattice spacing on the catalytic activities was investigated by comparing three different nickel-based nitrides which have different lattice spacing after introducing nitrogen.

\section{EXPERIMENTAL SECTION}

Synthesis of $\mathrm{Ni}_{3} \mathrm{Fe}-\mathrm{LDH}$. The $\mathrm{Ni}_{3} \mathrm{Fe}-\mathrm{LDH}$ nanosheets were synthesized based on previous procedures. ${ }^{44}$ In general, $\mathrm{Fe}\left(\mathrm{NO}_{3}\right)_{3} \cdot 9 \mathrm{H}_{2} \mathrm{O}(140 \mathrm{mg})$ and $\mathrm{NiCl}_{2}(188 \mathrm{mg})$ were dispersed into deionized (DI) water $(80 \mathrm{~mL})$ under severely stirring for $10 \mathrm{~min}$, followed by adding urea (168 $\mathrm{mg}$ ) and $\mathrm{Na}_{3} \mathrm{C}_{6} \mathrm{H}_{5} \mathrm{O}_{7}(5.16 \mathrm{mg})$. After another $10 \mathrm{~min}$, the reaction proceeded for $24 \mathrm{~h}$ with a Teflon-lined autoclave under $150{ }^{\circ} \mathrm{C}$. The $\mathrm{Ni}_{3} \mathrm{Fe}-\mathrm{LDH}$ was obtained after washing three times by ethanol and DI water.

Synthesis of $\mathrm{Ni}_{3} \mathrm{Co}-\mathrm{LDH}$. The $\mathrm{Ni}_{3} \mathrm{Co}-\mathrm{LDH}$ nanosheets were fabricated based on previous procedures. ${ }^{45}$ In general, $\mathrm{Ni}\left(\mathrm{NO}_{3}\right)_{2} \cdot 6 \mathrm{H}_{2} \mathrm{O}(727 \mathrm{mg}), \mathrm{CO}\left(\mathrm{NH}_{2}\right)_{2}(2.25 \mathrm{~g})$, and $\mathrm{Co}\left(\mathrm{NO}_{3}\right)_{2} \cdot 6 \mathrm{H}_{2} \mathrm{O}$ $(1153 \mathrm{mg})$ were dispersed into $\mathrm{DI}$ water to form a mixture $(50 \mathrm{~mL})$ with a volume ratio of $\mathrm{V}_{\text {(ethylene }}$ glycol) $/ \mathrm{V}_{\text {(DI water) }}=3: 1$. After refluxing $3 \mathrm{~h}$ under $90{ }^{\circ} \mathrm{C}$, the product was collected after washing three times by ethanol and DI water.

Synthesis of $\mathrm{Ni}_{3} \mathrm{Mn}-\mathrm{LDH}$. The $\mathrm{Ni}_{3} \mathrm{Mn}-\mathrm{LDH}$ nanosheets were synthesized with previous

procedures. ${ }^{46}$ In general, $\mathrm{Ni}\left(\mathrm{NO}_{3}\right)_{2} \cdot 6 \mathrm{H}_{2} \mathrm{O}(245 \mathrm{mg}), \mathrm{NaNO}_{3}(153 \mathrm{mg}), \mathrm{NH}_{4} \mathrm{~F}(185 \mathrm{mg})$, and 
$\mathrm{Mn}\left(\mathrm{NO}_{3}\right)_{2} \cdot 4 \mathrm{H}_{2} \mathrm{O}(50 \mathrm{mg})$ were added into DI water $(250 \mathrm{~mL})$ under severely stirring with $\mathrm{N}_{2}$ atmosphere. After 30 min, $\mathrm{H}_{2} \mathrm{O}_{2}$ (30 wt. \%, $25 \mu \mathrm{L}$ ) was added dropwise into the solution. $\mathrm{NaOH}$ solution $(50 \mathrm{~mL}, 0.12 \mathrm{M})$ was then dispersed dropwise into the solution. After stirring $12 \mathrm{~h}$ under room temperature, the product was collected after washing three times by ethanol and DI water.

Synthesis of holey 2D nitride nanosheets. To synthesize holey $2 \mathrm{D} \mathrm{Ni} 3 \mathrm{Fe}$ nitride, $\mathrm{Ni}_{3} \mathrm{Co}$ nitride, and $\mathrm{Ni}_{3} \mathrm{Mn}$ nitride nanosheets, $\mathrm{Ni}_{3} \mathrm{Fe} \mathrm{LDH}, \mathrm{Ni}_{3} \mathrm{Co} \mathrm{LDH}$, and $\mathrm{Ni}_{3} \mathrm{Mn} \mathrm{LDH}$ nanosheets were calcined $1 \mathrm{~min}$ at $\mathrm{NH}_{3}$ atmosphere at $500{ }^{\circ} \mathrm{C}\left(\right.$ ramp rate about $\left.10{ }^{\circ} \mathrm{C} \mathrm{min}^{-1}\right)$.

Materials characterizations. The crystalline structures were analyzed with GBC MMA powder X-ray diffraction. As for the morphologies, JEOL JSM-7500FA scanning electron microscopy and JEM-ARM200F transmission electron microscopy were utilized. Atomic force microscopy was from Asylum AFM facility. The specific surface areas were investigated through Quantachrome Instruments Autosorb iQ2 through $\mathrm{N}_{2}$ adsorption at $-196{ }^{\circ} \mathrm{C}$ with Brunauer-Emmett-Teller (BET) method. The vacuum pressure was kept under $10^{-4} \mathrm{~Pa}$ to degas the samples at $100^{\circ} \mathrm{C}$. The mean value was calculated after obtaining three measurements for each sample. The conductivities of the samples were measured by the four-probe method (9 T Physical Properties Measurement System).

Electrochemical measurements: A three-electrode glasscell with an $\mathrm{Ag} / \mathrm{AgCl}$ reference electrode and a graphite rod counter electrode on Princeton 2273 and 616 workstations were employed to test electrochemical performance. ${ }^{47}$ In order to make the catalyst inks, sample (5 $\mathrm{mg})$ was added in mixed solution $(1100 \mu \mathrm{L})$ with $5 \% \mathrm{Nafion}^{\circledR}$ solution $(100 \mu \mathrm{L})$, isopropanol (250 $\mu \mathrm{L})$, and DI water $(750 \mu \mathrm{L})$. The working electrodes were obtained through dripping the catalyst 
ink $(5 \mu \mathrm{L})$ on the pre-polished glassy carbon disk electrodes and drying for $20 \mathrm{~min}$ at $80{ }^{\circ} \mathrm{C}$ oven. Linear sweep voltammetry were performed use $1 \mathrm{M} \mathrm{KOH}$. Electrochemical impedance spectroscopy tests were conducted at $0.607 \mathrm{~V}$. To determine the active surface areas, electrochemical double-layer capacitance measurements was performed between 0.2 and $0.3 \mathrm{~V}$ at various scan rates. All potentials were referenced to reversible hydrogen electrode (RHE) with the following calculation: $E_{\mathrm{RHE}}=0.059 \mathrm{pH}+0.197+E_{\mathrm{Ag} / \mathrm{AgCl}}$. For the overall water-splitting performance, nickel foam $\left(1 \mathrm{~cm}^{2}\right)$ was utilized as working electrode. And the active material loading was $0.3 \mathrm{mg} \mathrm{cm}^{-2}$. SRI $8610 \mathrm{C}$ gas chromatograph was utilized to record the evaluated $\mathrm{H}_{2}$ gas during the overall water splitting. Faradaic efficiency is calculated with the following equation:

$$
\text { Faradaic efficiency }=\frac{V / V m}{Q /(2 * \mathrm{~F})}
$$

where $\mathrm{V}$ is the volume of $\mathrm{H}_{2}$ gas experimentally evolved, $\mathrm{V}_{\mathrm{m}}$ is the molar volume $\left(24.5 \mathrm{~L} \mathrm{~mol}^{-1}\right)$, Q stands for the number of charge travelled through two electrodes, 2 means 2 moles of electrons per mole for $\mathrm{H}_{2}$, and $\mathrm{F}$ represents the Faraday constant $\left(96485 \mathrm{C} \mathrm{mol}^{-1}\right)$.

Calculation Method: The Vienna Ab-initio Simulation Package package was utilized when carring out the density functional theory for the First-principle calculations. In order to define electronic exchange and correlation effects, the generalized gradient approximation with the Perdew-Burke-Ernzerhof functional was employed. For geometric optimization, MethfesselPaxton electronic smearing and uniform G-centered k-points meshes (resolution of $2 \pi^{*} 0.035 \AA^{-1}$ ) were employed for the Brillouin zone integration. One cutoff energy $(550 \mathrm{eV})$ was applied during the computations. Above parameters guarantee that the total energies convergence is below 1 meV/atom. After relax of the structure, forces between atoms were below $1 \mathrm{meV} \AA^{-1}$ with the complete stress tensor less than $0.01 \mathrm{GPa}$ of the target number. 


\section{RESEARCH AND DISCUSSION}

The synthesis strategy for the ultrathin 2D holey nitride materials is illustrated in Figure 1(a). The morphology and structure are characterized with scanning electron microscopy (SEM) and Xray diffraction (XRD). A series of nickel-based layered double hydroxide (LDH) nanosheets were synthesized as precursors, including $\mathrm{Ni}_{3} \mathrm{Fe} \mathrm{LDH}, \mathrm{Ni}_{3} \mathrm{Co} \mathrm{LDH}$, and $\mathrm{Ni}_{3} \mathrm{Mn} \mathrm{LDH}$, as illustrated in transmission electron microscopy (TEM) images (Figure 2a, d, g). All the LDH samples showed a uniform, silk-like, 2D nanosheet structure with big lateral size about several micrometers. In the following nitridation by annealing in an $\mathrm{NH}_{3}$ atmosphere, the corresponding nitride products were obtained with numerous holes on the in-plane surface, as revealed in Figure 1(b, c, d) and Figure 2(b, e, h), but the products still maintained the $2 \mathrm{D}$ nanosheet structure. All the nitride materials exhibit a standard cubic diffraction pattern corresponding to (111), (200), and (220) planes as shown in Figure 1(e, f). ${ }^{32-33,40}$ The distances of corresponding lattice spacing of $\mathrm{Ni}_{3} \mathrm{Fe}$ nitride is much larger than those of $\mathrm{Ni}_{3} \mathrm{Co}$ nitride and $\mathrm{Ni}_{3} \mathrm{Mn}$ nitride, which could modify the distance of

surface atoms with varying the surface electronic structure and catalytic activity. ${ }^{48-49}$ As can be seen from Figure S1, compared with metallic state samples, the peaks of three samples have been shifted to the left after introducing nitrogen, indicating that the nitrogen could increase the lattice spacing of the metallic state materials. The peak shifts of $\mathrm{Ni}_{3} \mathrm{Fe}$ is much larger than the $\mathrm{Ni}_{3} \mathrm{Co}$ and $\mathrm{Ni}_{3} \mathrm{Mn}$ as well, implying that the lattice spacing of $\mathrm{Ni}_{3} \mathrm{Fe}$ nitride is significantly increased after the induction of nitrogen. The morphology of the nitride materials is much more uniform than that of the oxide materials, indicating that the nitrogen also could assist the form of uniform nanopores on the nanosheets, as can be seen from Figure $\mathbf{S 2}$. 

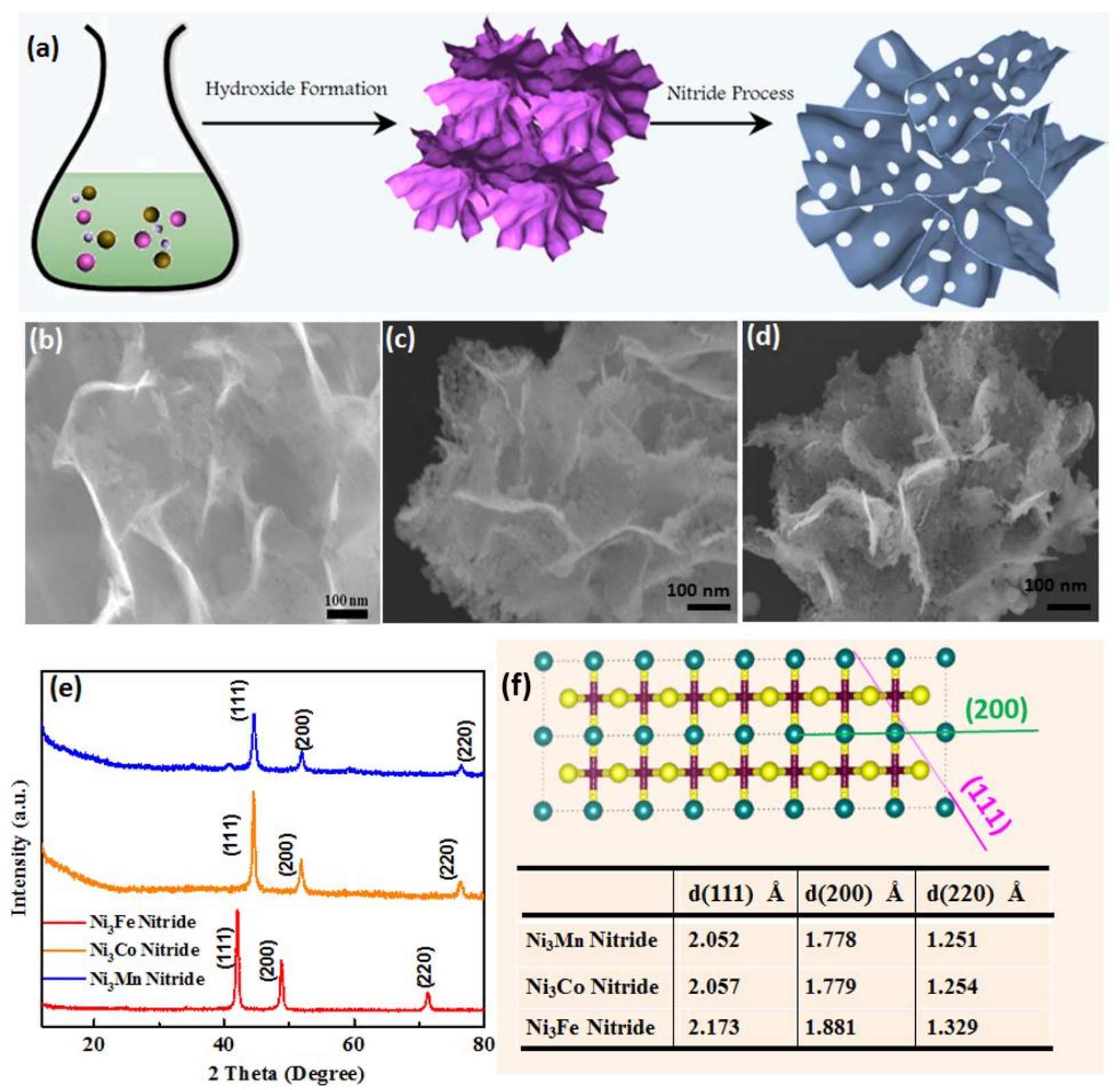

(f)

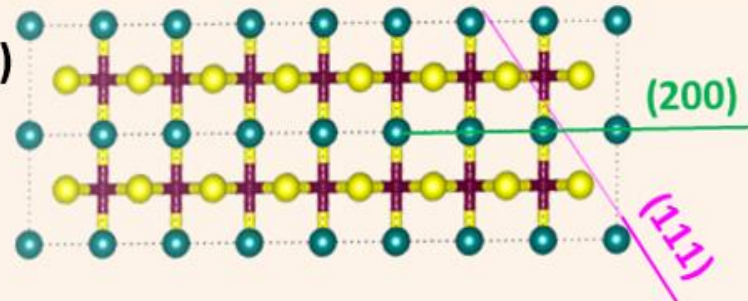

\begin{tabular}{l|l|l|l}
\hline & $d(111) \AA$ & $d(200) \AA$ & $d(220) \AA$ \\
\hline $\mathrm{Ni}_{3} \mathrm{Mn}$ Nitride & 2.052 & 1.778 & 1.251 \\
$\mathrm{Ni}_{3} \mathrm{Co}$ Nitride & 2.057 & 1.779 & 1.254 \\
$\mathrm{Ni}_{3} \mathrm{Fe}$ Nitride & 2.173 & 1.881 & 1.329 \\
\hline
\end{tabular}

Figure 1. (a) Fabrication process of $2 \mathrm{D}$ holey $\mathrm{Ni}_{3} \mathrm{M}$ nitride; SEM images of (b) $2 \mathrm{D}$ holey $\mathrm{Ni}_{3} \mathrm{Fe}$ nitride; (c) 2D holey $\mathrm{Ni}_{3} \mathrm{Co}$ nitride; (d) 2D holey Ni $3 \mathrm{Mn}$ nitride; (e) XRD pattern and (f) the corresponding distance of lattice plate.

The variations of the surface area and pore size range before and after nitridation process were further characterized, as shown in Figure 2. Taking $\mathrm{Ni}_{3} \mathrm{Fe}$ nitride for example, after the nitridation process, the specific surface area was dramatically enlarged from 114.9 to $189.6 \mathrm{~m}^{2} \mathrm{~g}^{-1}$, while numerous nanopores were generated, with the process primarily driven by the phase 
transformation and Kirkendall effect. ${ }^{13-14,50}$ Meanwhile, the specific surface area of $\mathrm{Ni}_{3} \mathrm{Co}$ nitride, and $\mathrm{Ni}_{3} \mathrm{Mn}$ nitride were dramatically increased from 125.6 to 197.2 , and from 108.5 to $168.3 \mathrm{~m}^{2} \mathrm{~g}^{-}$ 1, respectively. Compared to those deposited on porous substrate, such as nickel foam, a remarkable enhancement of specific surface area was got because the high weight ratio of the substrate will decrease the whole electrode specific surface area to some extent. ${ }^{51-52}$ It is concluded that designed ultrathin holey 2D structured nitrides can be successfully obtained by annealing the corresponding LDH precursors, and the surface area can be dramatically increased by the generation of numerous holes on the large lateral surface.

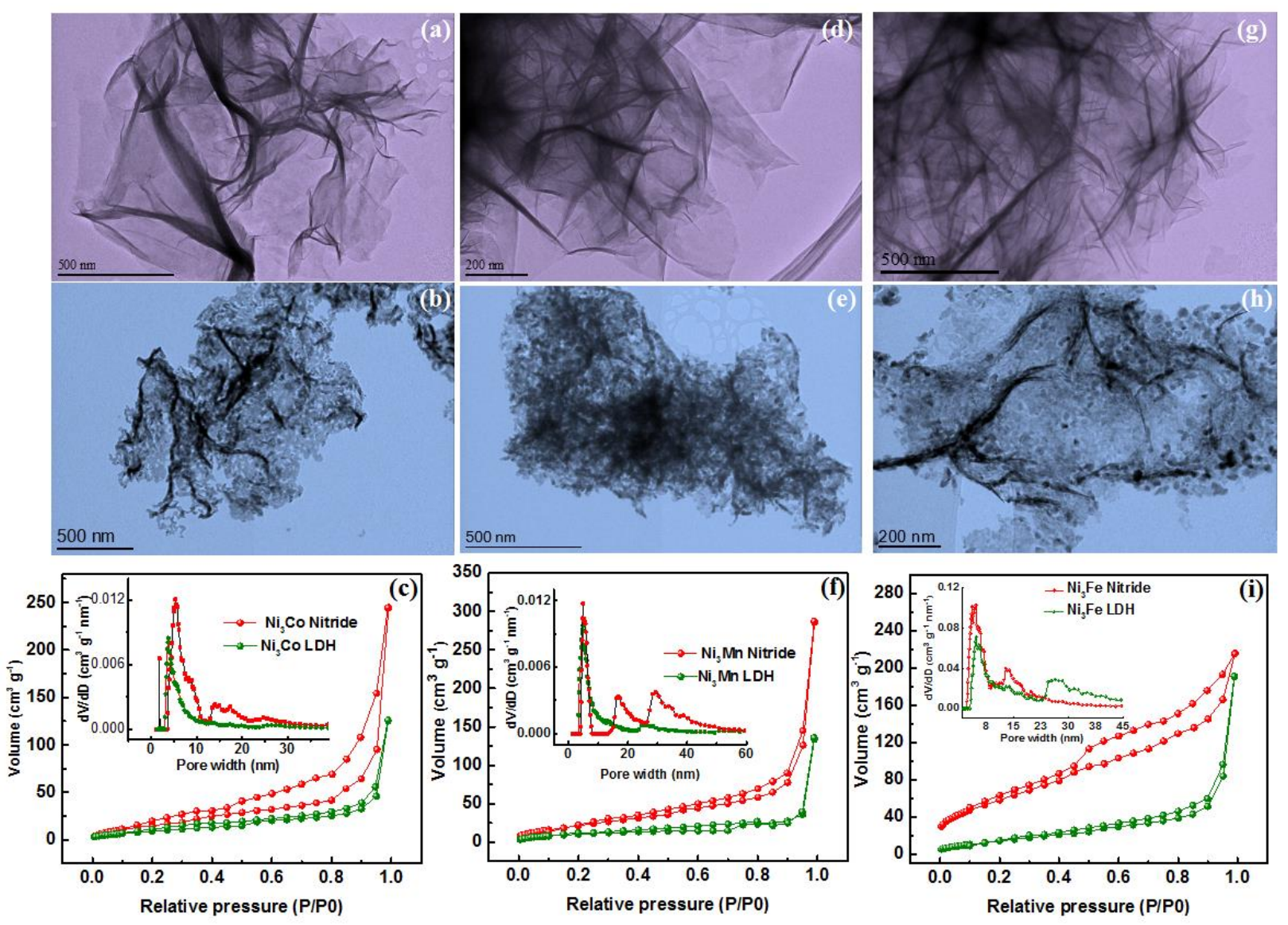

Figure 2. TEM images of $2 \mathrm{D}$ holey $\mathrm{Ni}_{3} \mathrm{M}(\mathrm{M}=\mathrm{Co}, \mathrm{Mn}, \mathrm{Fe}) \mathrm{LDH}$ nanosheets; $2 \mathrm{D}$ holey $\mathrm{Ni}_{3} \mathrm{M}(\mathrm{M}$ $=\mathrm{Co}, \mathrm{Mn}, \mathrm{Fe})$ nitride nanosheets and Specific surface area of 2D Ni $3 \mathrm{M}(\mathrm{M}=\mathrm{Co}, \mathrm{Mn}, \mathrm{Fe}) \mathrm{LDH}$ nanosheets and 2D holey $\mathrm{Ni}_{3} \mathrm{M}$ nitride nanosheets (c); inset: pore size distributions; (a - c) $\mathrm{M}=$

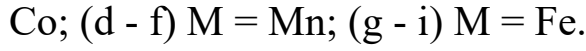


Morphological characterization of the as-fabricated materials was studied by scanning TEM energy-dispersive X-ray spectroscopy (STEM-EDS) and atomic force microscopy (AFM), as shown in Figure 3 and Figures S3-4. Compatible with the conclusions on the surface area and pore distribution, nitride materials present an obvious holey structure with pore size $\sim 15 \mathrm{~nm}$. Meanwhile, all the elements demonstrate a homogenous distribution over the whole area and maintain similar molar ratios (Figure S5 and Table S1). Furthermore, after the nitridation process, a solo phase component distribution still exists, which is compatible with the XRD. The AFM was employed to estimate the thickness and surface structure of the as-synthesized $2 \mathrm{D}$ holey $\mathrm{Ni}_{3} \mathrm{Fe}$ nitride nanosheets. As revealed in Figure 3g-j, the thickness of 2D holey $\mathrm{Ni}_{3} \mathrm{Fe}$ nitride nanosheets is within the range of $0.6-0.8 \mathrm{~nm}$, a thickness of approximately 3 atomic layers of (001) lattice planes. The trend in the curves also indicates the holey structure on the lateral 2D surfaces. Highangle annular dark-field STEM (HAADF-STEM) was utilized to characterize the structure of the ultrathin nitride nanosheets. As indicated in Figure 3k, 1 and Figures S6-7, in contrast to the intact surfaces, these holey nanosheets generate numerous edge areas and expose abundant lattice plates, which can thereby provide abundant catalytically active sites. More importantly, the ultrathin nanosheets show a nearly single-crystal structure with a strong high-orientation pattern, which can significantly increase the electrical conductivity. It is well acknowledged that there is a definite link between electrical conductivity and catalytic activity. High electrical conductivity can dramatically accelerate the kinetic rate of the catalytic reaction. ${ }^{39,44,53}$ Generally, the integration of the huge surface area, abundant defects the exposed catalytic sites near the edges, and the ultrahigh electrical conductivity resulting from the nearly single-crystal structure, as well as the connected holey architecture will make this type of nitride nanosheet a satisfactory electrocatalyst, particularly for gas generation processes. 

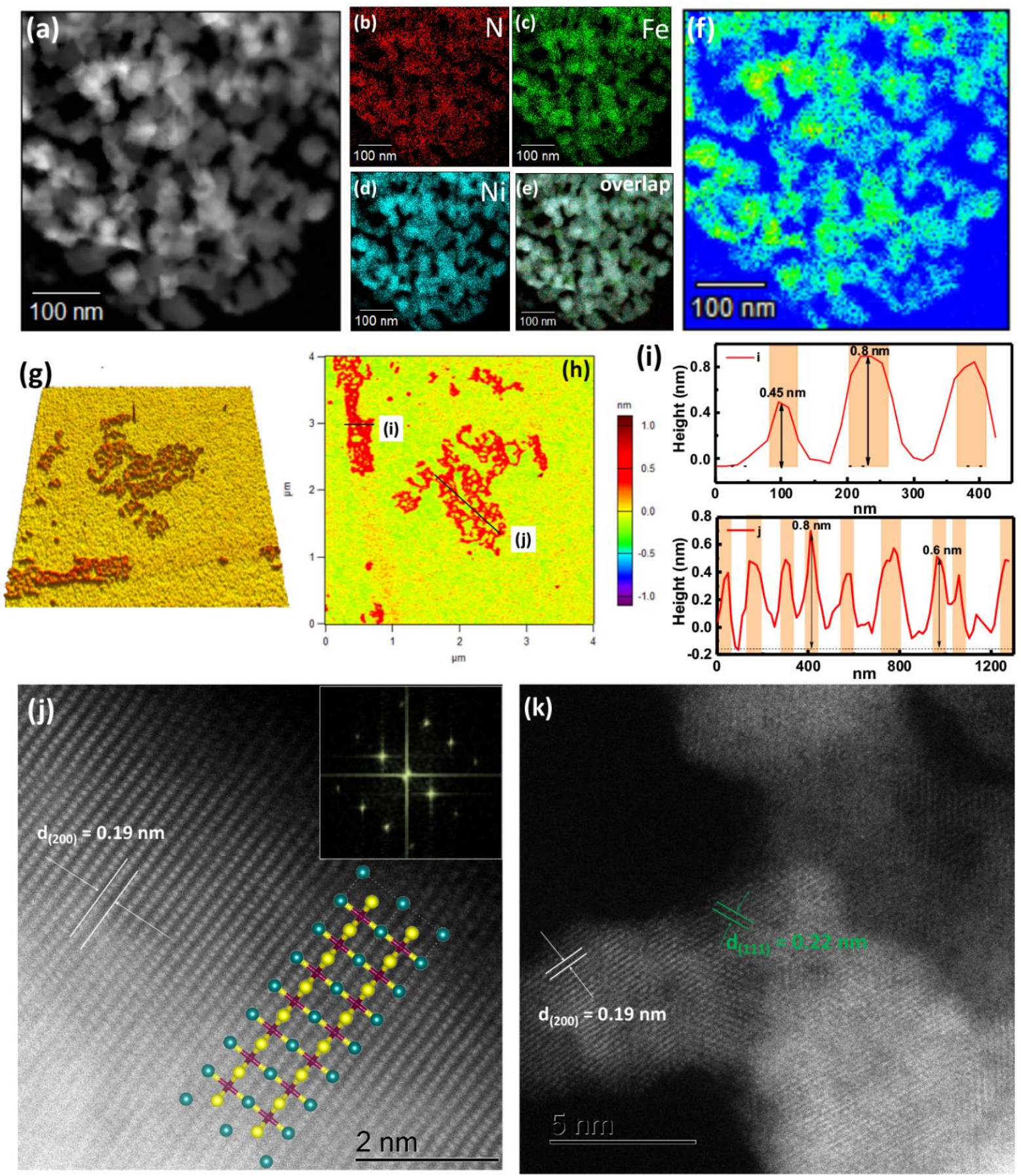

Figure 3. (a) HAADF-STEM image of holey $\mathrm{Ni}_{3} \mathrm{Fe}$ nitride nanosheets; (b-e) STEM-EDS mapping of (a); ( $\mathrm{f}$ ) the phase distribution in (a); (g-j) AFM results for the holey $\mathrm{Ni}_{3} \mathrm{Fe}$ nitride nanosheets; $(\mathrm{k}, 1)$ HAADF-STEM images of holey $\mathrm{Ni}_{3} \mathrm{Fe}$ nitride nanosheets; molecular diagram with fast Fourier transform (FFT) pattern as inset image in (k). 
A rotating disk electrode (RDE) was utilized to explore the electrocatalytic properties of these 2D structured materials, including LDH and holey nitride nanosheets, commercial $\mathrm{IrO}_{2}$ and $\mathrm{Pt} / \mathrm{C}$ with 1.0 M KOH. $\mathrm{IrO}_{2}$ was purchased from Sigma with the size about $100 \mathrm{~nm}$, as shown in Figure S8. The OER curves were investigated to determine each sample's OER catalytic activity based on mass-normalized current density (Figure 4a and Figure S9-12). It is obvious that the 2D holey $\mathrm{Ni}_{3} \mathrm{Fe}$ nitride nanosheets exhibit the highest current density compared with $\mathrm{Ni}_{3} \mathrm{Co}$ nitride, $\mathrm{Ni}_{3} \mathrm{Mn}$ nitride, and $\mathrm{IrO}_{2}$. A quite small overpotential $(300 \mathrm{mV})$ is required for the $2 \mathrm{D}$ holey $\mathrm{Ni}_{3} \mathrm{Fe}$ nitride nanosheets to deliver the current density about $100 \mathrm{~A} \mathrm{~g}^{-1}$, which is smaller than those of $2 \mathrm{D}$ holey $\mathrm{Ni}_{3} \mathrm{Co}$ nitride nanosheets $(340 \mathrm{mV}), 2 \mathrm{D}$ holey $\mathrm{Ni}_{3} \mathrm{Mn}$ nitride nanosheets $(429 \mathrm{mV})$, and $\mathrm{IrO}_{2}(465$ $\mathrm{mV})$. The small peak at $1.46 \mathrm{~V}$ of the $\mathrm{Ni}_{3} \mathrm{Fe}$ nitride could be ascribed to the redox reaction of $\mathrm{Ni}^{2+} / \mathrm{Ni}^{3+} / \mathrm{Ni}^{4+} .{ }^{54}$ The 2D nickel-based LDH and 2D nickel-based oxides nanosheets were also investigated for comparison (Figure S9 and Figure S10). To generate $100 \mathrm{~A} \mathrm{~g}^{-1}, 2 \mathrm{D} \mathrm{Ni} 3 \mathrm{Fe} \mathrm{LDH}$ nanosheets, 2 $\mathrm{D} \mathrm{Ni}_{3} \mathrm{Co} \mathrm{LDH}$ nanosheets, and 2D Ni${ }_{3} \mathrm{Mn} \mathrm{LDH}$ nanosheets required the overpotential of 413,430 , and $423 \mathrm{mV}$, respectively. Meanwhile, $2 \mathrm{D} \mathrm{Ni} 3 \mathrm{Fe}$ oxide nanosheets, $2 \mathrm{D} \mathrm{Ni}_{3} \mathrm{Co}$ oxide nanosheets, and 2D Ni$i_{3} \mathrm{Mn}$ oxide nanosheets required the overpotential of 357, 369, and $386 \mathrm{mV}$, respectively. It is clear that those $2 \mathrm{D} \mathrm{Ni} 3 \mathrm{M} \mathrm{LDH}$ nanosheet composites have higher overpotentials than their corresponding holey 2D nickel-based nitride nanosheet counterparts, which can be attributed to the excellent electrical conductivity, the architecture, and the numerous highly catalytically active sites. As revealed in Figure 4b, c, the excellent OER activities of the 2D holey $\mathrm{Ni}_{3} \mathrm{Fe}$ nitride nanosheets were further confirmed by using Tafel plots and overpotential. The $2 \mathrm{D}$ porous $\mathrm{Ni}_{3} \mathrm{Fe}$ nitride nanosheets has the smallest Tafel slope $\left(51 \mathrm{mV} \mathrm{dec}{ }^{-1}\right)$, indicating more enhanced OER kinetic activity for the holey $2 \mathrm{D} \mathrm{Ni} 3 \mathrm{Fe}$ nitride electrode when comparing with $\mathrm{Ni}_{3} \mathrm{Co}$ nitride $\left(55 \mathrm{mV} \mathrm{dec}^{-1}\right), \mathrm{Ni}_{3} \mathrm{Mn}$ nitride $\left(64 \mathrm{mV} \mathrm{dec}^{-1}\right)$, and $\mathrm{IrO}_{2}\left(69 \mathrm{mV} \mathrm{dec}^{-1}\right)$. As revealed in 
Figure $4 \mathrm{~d}$, the holey $2 \mathrm{D} \mathrm{Ni} 3 \mathrm{M}$ nitride nanosheets exhibit huge activity enhancements over the commercial $\mathrm{IrO}_{2}$, which could be due to excellent conductivity of the $\mathrm{Ni}_{3} \mathrm{M}$ nitrides and the holey nanosheets structure. In particular, the holey $2 \mathrm{D} \mathrm{Ni} 3 \mathrm{Fe}$ nitride nanosheets reveals the highest performance compared with $\mathrm{IrO}_{2}$. With overpotential of $300 \mathrm{mV}$, the $2 \mathrm{D}$ porous $\mathrm{Ni}_{3} \mathrm{Fe}$ nitride nanosheet sample shows an improvement over $\mathrm{IrO}_{2}$ by a factor of nearly 25 times. Moreover, we investigated the long-term electrocatalytic stability of these $2 \mathrm{D}$ holey $\mathrm{Ni}_{3} \mathrm{M}$ nitride nanosheets with high current density (100 $\mathrm{A} \mathrm{g}^{-1}$ ), as revealed in Figure 4e. Obviously, the holey 2D Ni 3 Fe nitride nanosheet electrode requires the lowest overpotential compared to the holey $2 \mathrm{D} \mathrm{Ni} \mathrm{N}_{3} \mathrm{Co}$ nitride nanosheets and holey $2 \mathrm{D} \mathrm{Ni} 3 \mathrm{Mn}$ nitride nanosheets, indicating its excellent stability and electrocatalytic activity. For comparison, $\mathrm{Ni}_{3} \mathrm{Fe}$ nitride nanoparticles with the size about $20 \mathrm{~nm}$ were also synthesized (Figure S11). As shown in Figure S12a, the $\mathrm{Ni}_{3} \mathrm{Fe}$ nitride nanoparticles also demonstrate a good OER performance, with a small overpotential $(303 \mathrm{mV})$. However, the stability of the $\mathrm{Ni}_{3} \mathrm{Fe}$ nitride nanoparticles is quite low compared with the $2 \mathrm{D}$ holey $\mathrm{Ni}_{3} \mathrm{Fe}$ nitride nanosheets. As demonstrated in Figure $\mathbf{S 1 2} \mathbf{b}$, the $\mathrm{Ni}_{3} \mathrm{Fe}$ nitride nanoparticles has significant performance decay, which could be contributed to the aggregation of the small nanoparticles. The excellent OER activities of the holey $2 \mathrm{D} \mathrm{Ni} 3 \mathrm{Fe}$ nitride nanosheets could be ascribed to its excellent electrical conductivity and the numerous catalytically active sites provided by the newly formed in-plane nanopores. Moreover, the metallic nitride products exhibit excellent electrical conductivity (Figure 4f, Figure S13, and Table S2), resulting from their metallic properties, highly-orientated crystalline texture, and large lattice spacing, which is also superior to those of reported nitride and other types of materials, such as sulfides, oxides and phosphates, primarily resulting from the highly orientated crystal structure. ${ }^{28,32,39}$ The electrical conductivity were further measured by four-probe method. The electrical conductivity of $\mathrm{Ni}_{3} \mathrm{Fe}$ nitride is $270 \mathrm{~S} \mathrm{~m}^{-1}$, 
which is higher than that of $\mathrm{Ni}_{3} \mathrm{Co}$ nitride $\left(200 \mathrm{~S} \mathrm{~m}^{-1}\right)$ and $\mathrm{Ni}_{3} \mathrm{Mn}$ nitride $\left(70 \mathrm{~S} \mathrm{~m}^{-1}\right)$. In addition, the highest conductivity of $\mathrm{Ni}_{3} \mathrm{Fe}$ nitride could be attributed to its larger crystal lattice, which could significantly facilitate the electron transport and leading to excellent conductivity.
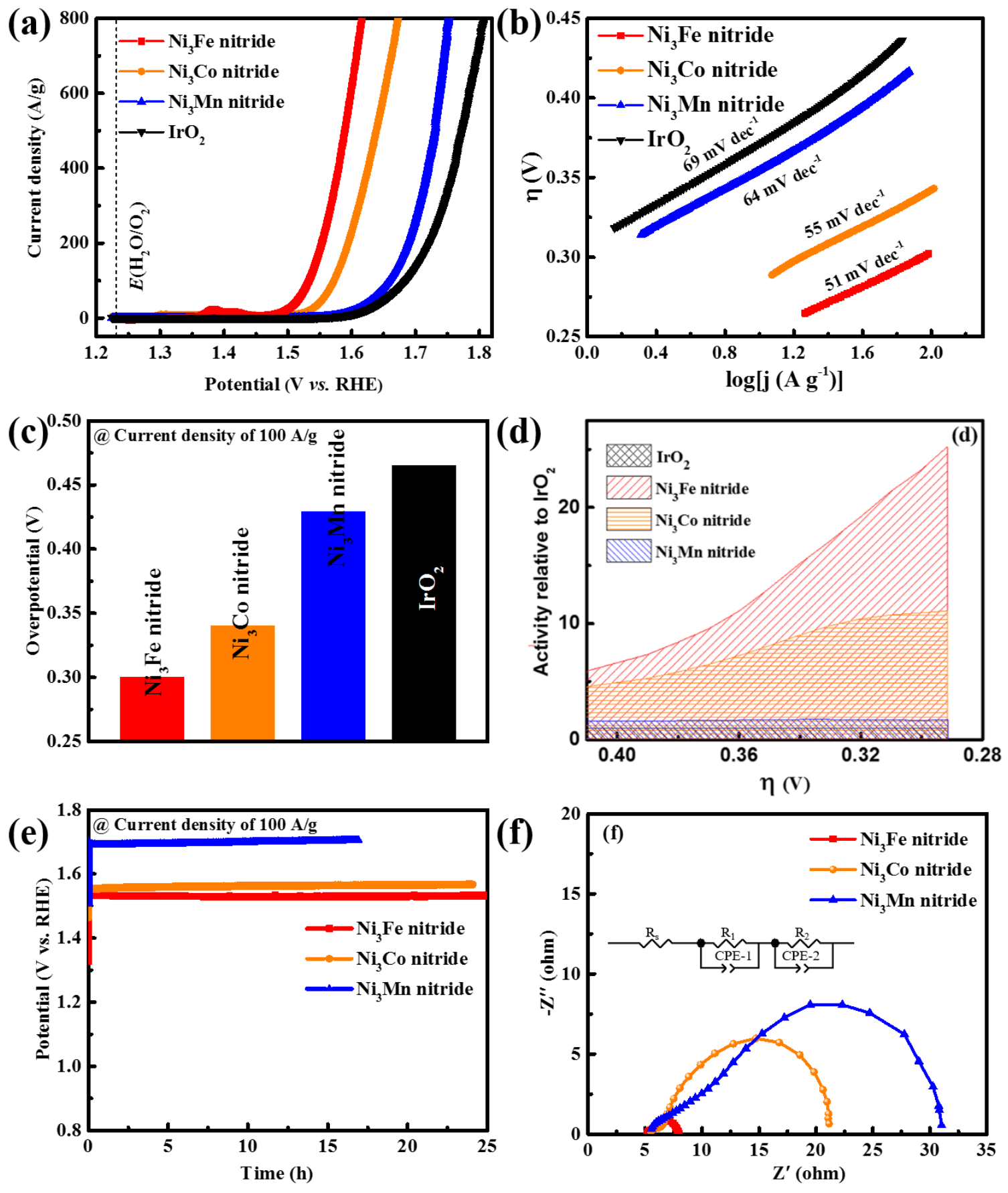
Figure 4. (a) Linear sweep voltammetrys (LSVs) of 2D holey $\mathrm{Ni}_{3} \mathrm{M}$ Nitride nanosheets and $\mathrm{IrO}_{2}$ with for the OER based on mass-normalized current density (scan rate of $10 \mathrm{mV} \mathrm{s}^{-1}$ ); (b) Tafel plots of 2D holey $\mathrm{Ni}_{3} \mathrm{M}$ Nitride nanosheets and $\mathrm{IrO}_{2}$; (c) The overpotential required to realize the current density of $100 \mathrm{~A} \mathrm{~g}^{-1}$; (d) Corresponding activity enhancement of 2D holey $\mathrm{Ni}_{3} \mathrm{M} \mathrm{Nitride}$ nanosheets relative to $\mathrm{IrO}_{2}$; (e) Stability curves of the 2D porous $\mathrm{Ni}_{3} \mathrm{M}$ nitride nanosheets; (f) Electrochemical impedance spectroscopy (EIS) curves of holey $\mathrm{Ni}_{3} \mathrm{M}$ nitride nanosheets, the equivalent circuit diagram as inset. RHE: reversible hydrogen electrode.

In addition, the electrocatalytic HER activities of these holey 2D Ni $3 \mathrm{M}$ nitride nanosheets were also studied in 1.0 M KOH (Ar-saturated). The holey 2D Ni33e nitride nanosheets electrode exhibited a quite tiny onset potential $(209 \mathrm{mV})$, which is just huger than $\mathrm{Pt} / \mathrm{C}(50 \mathrm{mV})$, but it is obviously smaller than those of the holey $2 \mathrm{D} \mathrm{Ni}_{3} \mathrm{Co}$ nitride nanosheets $(273 \mathrm{mV})$ and the holey $2 \mathrm{D}$ $\mathrm{Ni}_{3} \mathrm{Mn}$ nitride nanosheets $(282 \mathrm{mV}$ ) (Figure 5a-e). Also, the holey $2 \mathrm{D} \mathrm{Ni} 3 \mathrm{Fe}$ nitride nanosheets exhibited a small overpotential $(233 \mathrm{mV})$ to realize the current density about $-100 \mathrm{~A} \mathrm{~g}^{-1}$, which is only bigger than $\mathrm{Pt} / \mathrm{C}(95 \mathrm{mV})$ but smaller than the holey $2 \mathrm{D} \mathrm{Ni}$ Co nitride nanosheets $(319 \mathrm{mV})$ and the holey 2D Ni $3 \mathrm{Mn}$ nitride nanosheets $(451 \mathrm{mV})$. Moreover, the HER current density of the holey $2 \mathrm{D} \mathrm{Ni} 3 \mathrm{Fe}$ nitride nanosheets is considerable higher than those of the holey $2 \mathrm{D} \mathrm{Ni}{ }_{3} \mathrm{Co}$ nitride nanosheets and the holey $2 \mathrm{D} \mathrm{Ni}_{3} \mathrm{Mn}$ nitride nanosheets at a given voltage. For instance, the current density of the $2 \mathrm{D}$ holey $\mathrm{Ni}_{3} \mathrm{Fe}$ nitride nanosheets is $-492.4 \mathrm{~A} \mathrm{~g} \mathrm{~g}^{-1}$ with overpotential about $300 \mathrm{mV}$. This is 6.54 and 12.54 times higher than those of the holey $2 \mathrm{D} \mathrm{Ni} 3 \mathrm{Co}$ nitride nanosheets and the holey $2 \mathrm{D} \mathrm{Ni} \mathrm{Ni}_{3} \mathrm{Mitride}$ nanosheets, respectively. Meanwhile, the holey $2 \mathrm{D} \mathrm{Ni}_{3} \mathrm{Fe}$ nitride nanosheets demonstrated an enhanced reaction kinetic rate with a lower Tafel slope than for the commercial Pt/C. After 1000 cycles, there is no obvious passivation of catalytic activity, as shown in Figure 5(f). On basis of the above results, it is clear that the holey $2 \mathrm{D}$ nickel-based nitrides nanosheets derived from 2D nickel-based LDH nanosheets have significantly enhanced OER and HER catalytic activities. The improved catalytic activities can be due to the excellent conductivity 
of the $\mathrm{Ni}_{3} \mathrm{M}$ nitrides, abundant active sites, and huge surface area provided by the $2 \mathrm{D}$ holey nanosheet structure. It is clear that the $2 \mathrm{D}$ holey $\mathrm{Ni}_{3} \mathrm{Fe}$ nitride nanosheets with holey nanostructure exhibit a lower overpotential used as OER and HER bifunctional electrocatalyst.
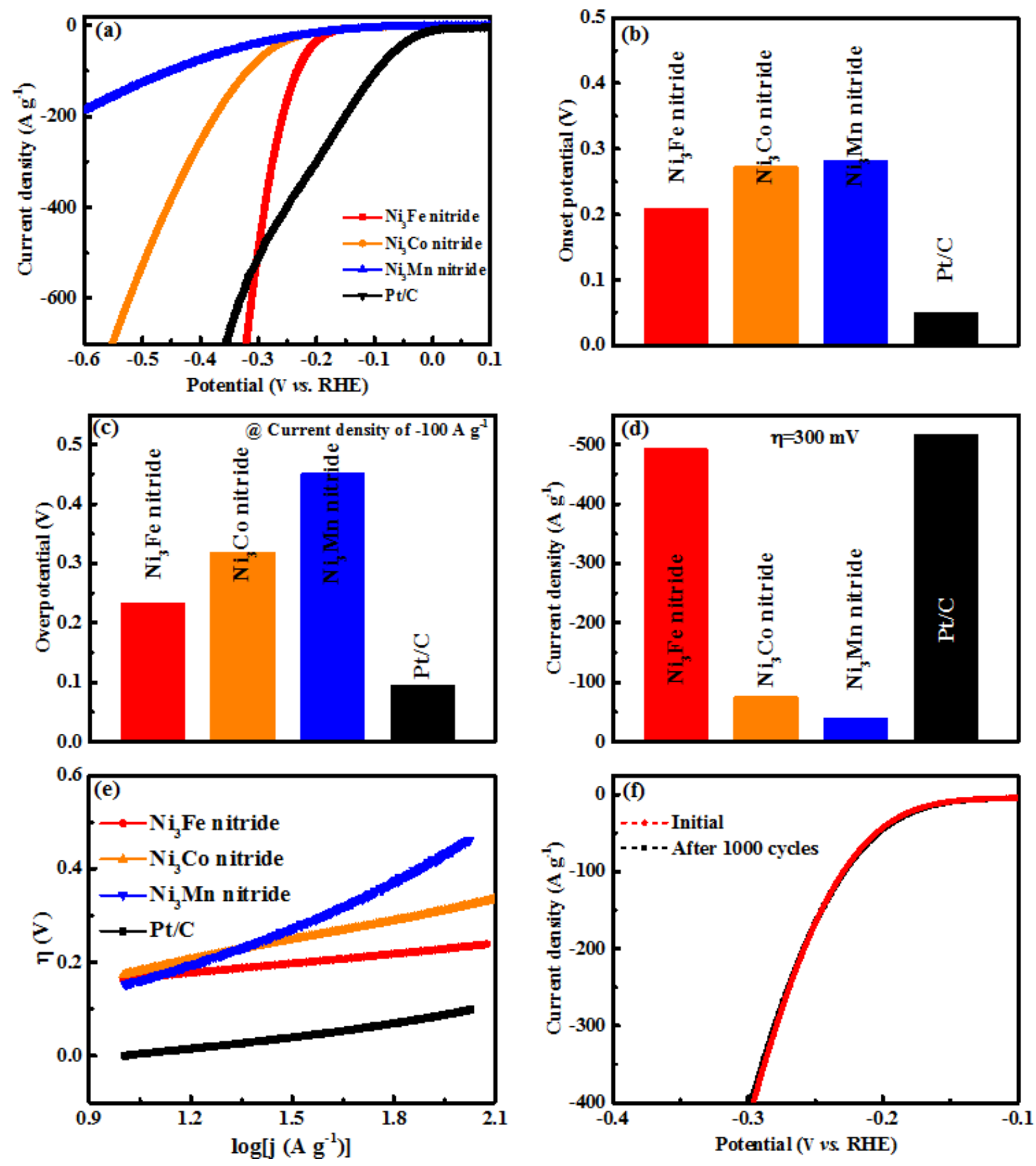

Figure 5. (a) LSVs of $2 \mathrm{D}$ holey $\mathrm{Ni}_{3} \mathrm{M}$ nitride nanosheets and $\mathrm{Pt} / \mathrm{C}$ for the HER based on massnormalized current density (scan rate of $10 \mathrm{mV} \mathrm{s}^{-1}$ ); (b) Comparison of the onset potentials; (c) 
The overpotential required for achieve the current density of $100 \mathrm{~A} \mathrm{~g}^{-1}$; (d) Current density at $\eta=$ $-300 \mathrm{mV}$; (e) The corresponding Tafel plots for $2 \mathrm{D}$ holey $\mathrm{Ni}_{3} \mathrm{M}$ nitride nanosheets and $\mathrm{Pt} / \mathrm{C}$; (f) LSV curves of holey 2D Ni $\mathrm{Fe}$ nitride nanosheets before and after 1000 cycles.

It is well known that there is a definite link between catalytic performance and active surface area, therefore, the electrochemical surface area (ECSA) was calculated through the corresponding electrochemical double-layer capacitance $\left(\mathrm{C}_{\mathrm{dl}}\right)$ to demonstrate the advantages of the $2 \mathrm{D}$ holey nanosheets structure in determining the catalytic activity. ${ }^{55-58}$ The slope of capacitive current density $\left(\Delta \mathrm{j}=\mathrm{j}_{\text {anode }}-\mathrm{j}_{\text {cathode }}\right)$ at $1.273 \mathrm{~V}$ against different scan rates is twice of the $\mathrm{C}_{\mathrm{dl}}$, utilized to stand for the corresponding ECSA. Typical CV curves of $\mathrm{Ni}_{3} \mathrm{Fe}$ nitride, $\mathrm{Ni}_{3} \mathrm{Co}$ nitride, $\mathrm{Ni}_{3} \mathrm{Mn}$ nitride, and nickel-based LDH in different scan rates are shown in Figure 6(a - c) and Figure S14. As can be seen in Figure 6(d), 2D holey $\mathrm{Ni}_{3} \mathrm{Fe}$ nitride exhibits the largest $\mathrm{C}_{\mathrm{dl}}$ compared with those of the other catalysts. From LDH to 2D holey nitride, the ECSA values increased by around twice. This increase is mainly assigned to the formation of abundant defects and uniform nanopores on the nanosheets during the nitridation process. More importantly, compared with $2 \mathrm{D}$ holey $\mathrm{Ni}_{3} \mathrm{Co}$ nitride and $\mathrm{Ni}_{3} \mathrm{Mn}$ nitride nanosheets, 2D holey $\mathrm{Ni}_{3} \mathrm{Fe}$ nitride nanosheets has $104.2 \%$ and 128.8 \% higher ECSA, more than 9 - fold and 64 - fold times of OER current density at $\eta=320 \mathrm{mV}$ achieved, respectively. Such enhancement of the electrocatalytic activity can not only be ascribed to the larger surface area, but also due to the higher intrinsic catalytic activity due to the significantly enlarged lattice spacing after introducing nitrogen, leading to much more electrochemically accessible inner layer surface. 

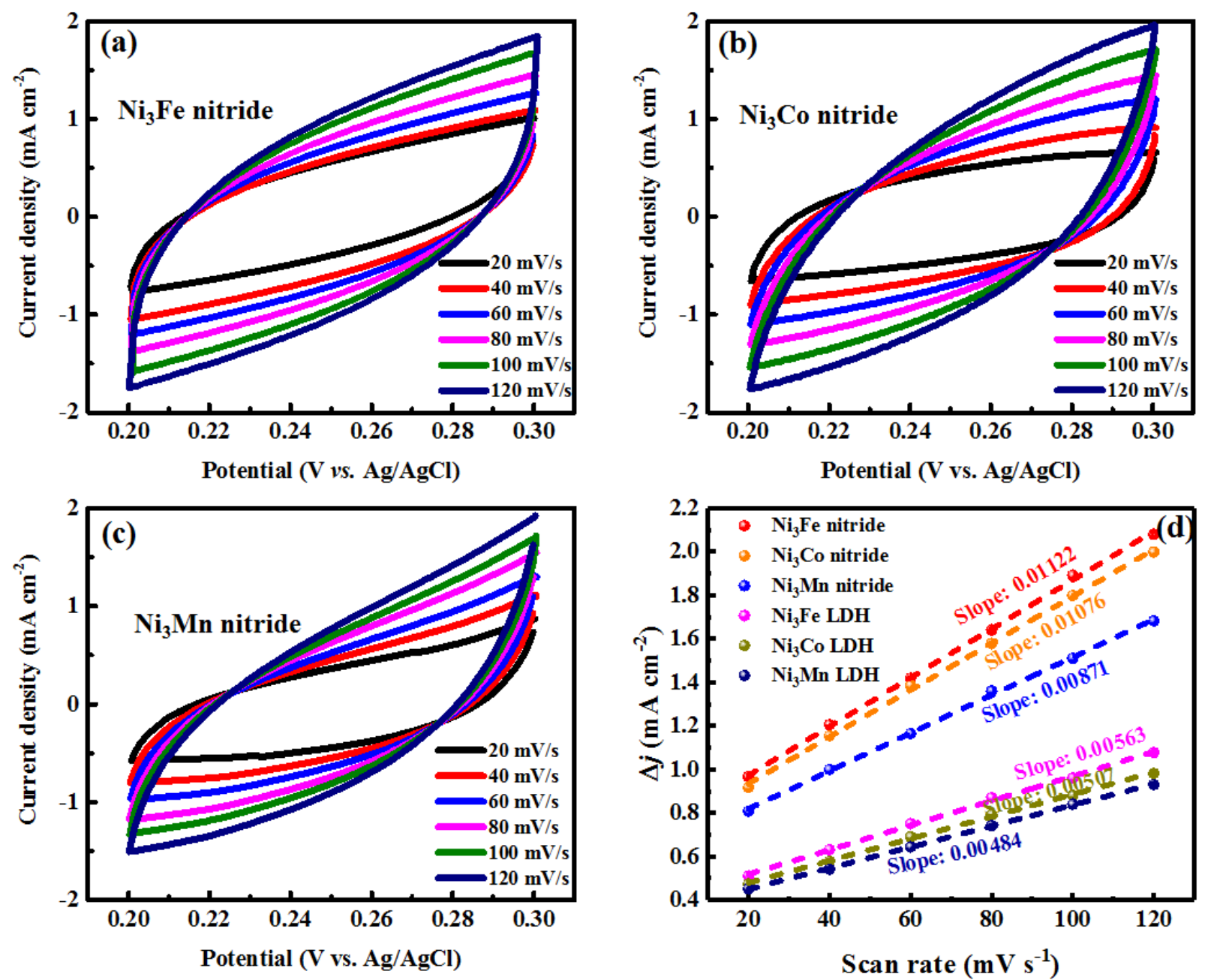

Figure 6. Typical $\mathrm{CV}$ curves of (a) $\mathrm{Ni}_{3} \mathrm{Fe}$ nitride, (b) $\mathrm{Ni}_{3} \mathrm{Co}$ nitride, and (c) $\mathrm{Ni}_{3} \mathrm{Mn}$ nitride in $1 \mathrm{M}$ $\mathrm{KOH}$ with various scan rates. (d) Differences of current density $\left(\Delta \mathrm{j}=\mathrm{j}_{\text {anode }}-\mathrm{j}_{\text {cathode }}\right)$ at $1.273 \mathrm{~V}$ plotted vs. the scan rates. The $\mathrm{C}_{\mathrm{dl}}$ is half of the slope.

The overall water-splitting performance of $2 \mathrm{D}$ holey $\mathrm{Ni}_{3} \mathrm{Fe}$ nitride nanosheets was evaluated in 1.0 $\mathrm{M} \mathrm{KOH}$, in which $\mathrm{Ni}_{3} \mathrm{Fe}$ nitride was utilized as electrocatalyst both at the two electrodes. The electrocatalyst achieved a current density about $100 \mathrm{~A} \mathrm{~g}^{-1}$ at $1.60 \mathrm{~V}$ (Figure S15a). The inset in Figure S15a reveals the formation of oxygen and hydrogen bubbles on the nickel foam. The electrolyser exhibits considerable overall water-splitting durability for over $10 \mathrm{~h}$ with no obvious performance decay (Figure S15b). The Faradaic efficiency of this electrolyser was determined with chronopotentiometry over $120 \mathrm{~min}$ (inset in Figure S15b). The inset in Figure S15b 
demonstrated that the $\mathrm{H}_{2}$ generated experimentally were similar with the theoretically calculated results during this time. The overall water-splitting has a very high Faradaic efficiency (close to $100 \%$ ). These results also suggest that the $2 \mathrm{D}$ holey $\mathrm{Ni}_{3} \mathrm{Fe}$ nitride nanosheets are promising bifunctional electrocatalysts for economically efficient water-splitting electrocatalysts.

Even after $1000 \mathrm{CV}$ cycles, the $\mathrm{Ni}_{3} \mathrm{Fe}$ nitride nanosheets still preserve the 2D holey morphology (Figure S16a). HRTEM image indicates that there is a quite thin oxides layer about 1-2 $\mathrm{nm}$ on the $\mathrm{Ni}_{3} \mathrm{Fe}$ nitride nanosheets (Figure $\mathrm{S} 16 \mathrm{~b}$ ), suggesting the oxidization of $\mathrm{Ni}_{3} \mathrm{Fe}$ nitride nanosheets. The compositions changes of the $2 \mathrm{D}$ holey $\mathrm{Ni}_{3} \mathrm{Fe}$ nitride nanosheets after $1000 \mathrm{CV}$ cycles were explored with X-ray photoelectron spectroscopy (XPS), as revealed in Figure S16d - f. The peaks of $\mathrm{Ni}^{2+}$ and $\mathrm{Fe}^{3+}$ indicate that the existence of surface oxidation in $\mathrm{Ni}_{3} \mathrm{Fe}$ nitride nanosheets into $\mathrm{NiFe}$ oxide/hydroxide. However, there is no $\mathrm{NiFe}$ oxide/hydroxide diffraction peak, indicating the main phase was still $\mathrm{Ni}_{3} \mathrm{Fe}$ nitride (Figure $\mathrm{S} 16 \mathrm{c}$ ). In addition, there is no significant elements contents changes before and after CV cycles (Table S3). All of the above characterizations provide solid evidence that the major phases are $\mathrm{Ni}_{3} \mathrm{Fe}$ nitride with a very thin oxide layer during the catalytic process.

To further investigate and understand the enhanced OER and HER performance of the $\mathrm{Ni}_{3} \mathrm{Fe}$ nitride, the oxygen adsorption energy $\left(\mathrm{E}_{\mathrm{O}}\right)$ and hydrogen adsorption energy $\left(\mathrm{E}_{\mathrm{H}}\right)$ on the $\mathrm{Ni}_{3} \mathrm{Fe}$ nitride (111) and (200) lattice were studied by conducting density functional theory (DFT) calculations. Figure S17a-d and Table S4 reveal that the (111) lattice possesses more moderate hydrogen adsorption energy $(-1.18 \mathrm{eV})$ and oxygen adsorption energy $(-3.47 \mathrm{eV})$ than these of the (200) lattice (-3.87 and $-6.93 \mathrm{eV}$, respectively), indicating that the (111) lattice is more favorable 
than the (200) lattice for the OER and HER reactions. DFT calculations for the $E_{O}$ and $E_{H}$ on the $\mathrm{Ni}_{3} \mathrm{Fe}$ nitride (111), $\mathrm{Ni}_{3} \mathrm{Co}$ nitride (111), and $\mathrm{Ni}_{3} \mathrm{Mn}$ nitride (111) were further conducted. Figure S17c-h and Table $\mathbf{S} 4$ demonstrate that the $\mathrm{Ni}_{3} \mathrm{Fe}$ nitride (111) possesses a moderate oxygen adsorption energy $(-3.47 \mathrm{eV})$, which is favorable for the OER reaction than that of $\mathrm{Ni}_{3} \mathrm{Co}$ nitride (111) (-2.80 eV) and $\mathrm{Ni}_{3} \mathrm{Mn}$ nitride (111) (-3.29 eV). In addition, $\mathrm{Ni}_{3} \mathrm{Fe}$ nitride (111) also exhibits optimized hydrogen adsorption energy $(-1.18 \mathrm{eV})$ when compared with $\mathrm{Ni}_{3} \mathrm{Co}$ nitride (111) (-0.67 $\mathrm{eV})$ and $\mathrm{Ni}_{3} \mathrm{Mn}$ nitride (111) (-0.59 eV). The above calculations could prove that the larger lattice spacing could enhance the catalytic activities through changing the hydrogen adsorption energy and oxygen adsorption energy.

\section{CONCLUSIONS}

In summary, ultrathin holey 2D nickel-based nitride lateral nanosheets (less than $1 \mathrm{~nm}$ thick) were designed and successfully synthesized by nitridation treatment of the corresponding hydroxide precursors. Owing to the highly-orientated crystalline texture, large lattice spacing, abundant exposed catalytically active sites resulting both from the atoms on the large lateral surfaces and the areas near the edges of the generated holes, as well as the hierarchical porous continuously conductive architecture suitable for transport of intermediate reaction products and diffusion of generated gases, these metallic nitride holey nanosheets showed excellent electrocatalytic property for the OER and HER. Among them, the ultrathin holey $2 \mathrm{D} \mathrm{Ni} \mathrm{NFe}_{3}$ nitride nanosheets demonstrated a quite lower overpotential $(300 \mathrm{mV})$ towards oxygen evolution to deliver a current density of $100 \mathrm{~A} \mathrm{~g} \mathrm{~g}^{-1}$, a large enhancement over commercial $\mathrm{IrO}_{2}$ by a factor of nearly 25 times. Meanwhile, they also accelerate the catalytic HER with a tiny overpotential (233 
$\mathrm{mV}$ ) to achieve the current density about $100 \mathrm{~A} \mathrm{~g}^{-1}$, a kinetic rate higher than commercial $\mathrm{Pt} / \mathrm{C}$ catalytic activity. The robust electrocatalytic activity of $2 \mathrm{D} \mathrm{Ni} 3 \mathrm{Fe}$ nitride nanosheets is largely ascribed to the enhanced electrochemical surface area, owing to the larger surface area and excellent intrinsic electrocatalytic property due to the significantly enlarged lattice spacing after introducing nitrogen, leading to much more electrochemically accessible inner layer surface. Therefore, in this work, the concept of designing 2D ultrathin highly-orientated and holey nitride nanosheets has been explored for electrocatalyst application.

\section{ASSOCIATED CONTENT}

Supporting Information

The Supporting Information is available free of charge on the ACS Publications website.

Additional STEM, EDS, OER, and EIS (PDF)

\section{AUTHOR INFORMATION}

\section{Corresponding Authors}

*E-mail for W.B. Luo: luow@uow.edu.au

*E-mail for J.Z. Wang: jiazhao@uow.edu.au

\section{Notes}

The authors declare no competing financial interest.

\section{ACKNOWLEDGEMENTS}


This work is financially supported by the Australian Research Council (ARC) through a Discovery Project (DP140100401) and ARC-LIEF Grants (LE120100104 and LE0237478).The authors appreciate Dr. Tania Silver to polish the manuscript with English editing, and also thank the UOW Electron Microscopy Centre for the use of the equipment, with specific acknowledgements to Dr. Gilberto Casillas-Garcia. All the authors have discussed and approved the final revised version of the manuscript.

\section{REFERENCES}

1. $\quad$ Bhimanapati, G. R.; Lin, Z.; Meunier, V.; Jung, Y.; Cha, J.; Das, S.; Xiao, D.; Son, Y.; Strano, M. S.; Cooper, V. R.; Liang, L.; Louie, S. G.; Ringe, E.; Zhou, W.; Kim, S. S.; Naik, R. R.; Sumpter, B. G.; Terrones, H.; Xia, F.; Wang, Y.; Zhu, J.; Akinwande, D.; Alem, N.; Schuller, J. A.; Schaak, R. E.; Terrones, M.; Robinson, J. A., Recent Advances in Two-Dimensional Materials beyond Graphene. ACS Nano 2015, 9, 11509-11539.

2. Tan, C.; Cao, X.; Wu, X.-J.; He, Q.; Yang, J.; Zhang, X.; Chen, J.; Zhao, W.; Han, S.; Nam, G.-H.; Sindoro, M.; Zhang, H., Recent Advances in Ultrathin Two-Dimensional Nanomaterials. Chem. Rev. 2017, 117, 6225-6331.

3. Chhowalla, M.; Liu, Z.; Zhang, H., Two-dimensional transition metal dichalcogenide (TMD) nanosheets. Chem. Soc. Rev. 2015, 44, 2584-2586.

4. $\quad$ Dou, Y.; Zhang, L.; Xu, X.; Sun, Z.; Liao, T.; Dou, S. X., Atomically thin non-layered nanomaterials for energy storage and conversion. Chem. Soc. Rev. 2017, 46, 7338-7373.

5. Khan, A. H.; Ghosh, S.; Pradhan, B.; Dalui, A.; Shrestha, L. K.; Acharya, S.; Ariga, K., Two-Dimensional (2D) Nanomaterials towards Electrochemical Nanoarchitectonics in EnergyRelated Applications. Bull. Chem. Soc. Jpn. 2017, 90, 627-648.

6. Chen, P.; Zhang, Z.; Duan, X.; Duan, X., Chemical synthesis of two-dimensional atomic crystals, heterostructures and superlattices. Chem. Soc. Rev. 2018, 47, 3129-3151.

7. $\quad$ Butler, S. Z.; Hollen, S. M.; Cao, L.; Cui, Y.; Gupta, J. A.; Gutiérrez, H. R.; Heinz, T. F.; Hong, S. S.; Huang, J.; Ismach, A. F.; Johnston-Halperin, E.; Kuno, M.; Plashnitsa, V. V.; Robinson, R. D.; Ruoff, R. S.; Salahuddin, S.; Shan, J.; Shi, L.; Spencer, M. G.; Terrones, M.; Windl, W.; Goldberger, J. E., Progress, Challenges, and Opportunities in Two-Dimensional Materials Beyond Graphene. ACS Nano 2013, 7, 2898-2926.

8. Zhang, H., Ultrathin Two-Dimensional Nanomaterials. ACS Nano 2015, 9, 9451-9469.

9. Shi, Y.; Li, H.; Li, L.-J., Recent advances in controlled synthesis of two-dimensional transition metal dichalcogenides via vapour deposition techniques. Chem. Soc. Rev. 2015, 44, $2744-2756$. 
10. Tan, C.; Zhang, H., Two-dimensional transition metal dichalcogenide nanosheet-based composites. Chem. Soc. Rev. 2015, 44, 2713-2731.

11. Auxilia, F. M.; Ishihara, S.; Mandal, S.; Tanabe, T.; Saravanan, G.; Ramesh, G. V.; Umezawa, N.; Hara, T.; Ya Xu, Y.; Hishita, S.; Yamauchi, Y.; Dakshanamoorthy, A.; Hill, J. P.; Ariga, K.; Abe, H. Low-Temperature Remediation of $\mathrm{NO}$ Catalyzed by Interleaved $\mathrm{CuO}$ Nanoplates. Adv. Mater. 2014, 26, 4481-4485.

12. Wang, K.; Wei, M.; Morris, M. A.; Zhou, H.; Holmes, J. D., Mesoporous Titania Nanotubes: Their Preparation and Application as Electrode Materials for Rechargeable Lithium Batteries. Adv. Mater. 2007, 19, 3016-3020.

13. Xia, X.; Wang, Y.; Ruditskiy, A.; Xia, Y., 25th Anniversary Article: Galvanic Replacement: A Simple and Versatile Route to Hollow Nanostructures with Tunable and Well-Controlled Properties. Adv. Mater. 2013, 25, 6313-6333.

14. Luo, W.-B.; Gao, X.-W.; Chou, S.-L.; Wang, J.-Z.; Liu, H.-K., Porous AgPd-Pd Composite Nanotubes as Highly Efficient Electrocatalysts for Lithium-Oxygen Batteries. $A d v$. Mater. 2015, 27, 6862-6869.

15. Feng, J. X.; Xu, H.; Dong, Y. T.; Ye, S. H.; Tong, Y. X.; Li, G. R., FeOOH/Co/FeOOH Hybrid Nanotube Arrays as High-Performance Electrocatalysts for the Oxygen Evolution Reaction. Angew. Chem., Int. Ed. 2016, 55, 3694-3698.

16. Feng, J. X.; Ye, S. H.; Xu, H.; Tong, Y. X.; Li, G. R., Design and Synthesis of $\mathrm{FeOOH} / \mathrm{CeO} 2$ Heterolayered Nanotube Electrocatalysts for the Oxygen Evolution Reaction. Adv Mater 2016, 28, 4698-4703.

17. Lu, X. F.; Gu, L. F.; Wang, J. W.; Wu, J. X.; Liao, P. Q.; Li, G. R., Bimetal-Organic Framework Derived CoFe2 O4 /C Porous Hybrid Nanorod Arrays as High-Performance Electrocatalysts for Oxygen Evolution Reaction. Adv Mater 2017, 29, 1604437.

18. Ye, S. H.; Shi, Z. X.; Feng, J. X.; Tong, Y. X.; Li, G. R., Activating CoOOH Porous Nanosheet Arrays by Partial Iron Substitution for Efficient Oxygen Evolution Reaction. Angew. Chem., Int. Ed. 2018, 57, 2672-2676.

19. Sun, Y.; Gao, S.; Lei, F.; Xie, Y., Atomically-thin two-dimensional sheets for understanding active sites in catalysis. Chem. Soc. Rev. 2015, 44, 623-636.

20. Chen, D.; Peng, L.; Yuan, Y.; Zhu, Y.; Fang, Z.; Yan, C.; Chen, G.; Shahbazian-Yassar, R.; Lu, J.; Amine, K.; Yu, G., Two-Dimensional Holey Co3O4 Nanosheets for High-Rate AlkaliIon Batteries: From Rational Synthesis to in Situ Probing. Nano Lett. 2017, 17, 3907-3913.

21. Duan, X.; Wang, C.; Pan, A.; Yu, R.; Duan, X., Two-dimensional transition metal dichalcogenides as atomically thin semiconductors: opportunities and challenges. Chem. Soc. Rev. 2015, 44, 8859-8876.

22. Luo, W.-B.; Gao, X.-W.; Shi, D.-Q.; Chou, S.-L.; Wang, J.-Z.; Liu, H.-K., Binder-Free and Carbon-Free 3D Porous Air Electrode for Li-O2 Batteries with High Efficiency, High Capacity, and Long Life. Small 2016, 12, 3031-3038.

23. Wang, P.; Pu, Z.; Li, Y.; Wu, L.; Tu, Z.; Jiang, M.; Kou, Z.; Amiinu, I. S.; Mu, S., IronDoped Nickel Phosphide Nanosheet Arrays: An Efficient Bifunctional Electrocatalyst for Water Splitting. ACS Appl. Mater. Interfaces 2017, 9, 26001-26007.

24. Pu, Z.; Amiinu, I. S.; Zhang, C.; Wang, M.; Kou, Z.; Mu, S., Phytic acid-derivative transition metal phosphides encapsulated in N,P-codoped carbon: an efficient and durable hydrogen evolution electrocatalyst in a wide $\mathrm{pH}$ range. Nanoscale 2017, 9, 3555-3560. 
25. Pu, Z. H.; Xue, Y.; Li, W. Q.; Amiinu, I. S.; Mu, S. C., Efficient water splitting catalyzed by flexible NiP2 nanosheet array electrodes under both neutral and alkaline solutions. New J. Chem. 2017, 41, 2154-2159.

26. Pu, Z.; Zhang, C.; Amiinu, I. S.; Li, W.; Wu, L.; Mu, S., General Strategy for the Synthesis of Transition-Metal Phosphide/N-Doped Carbon Frameworks for Hydrogen and Oxygen Evolution. ACS Appl. Mater. Interfaces 2017, 9, 16187-16193.

27. Chen, P.; Zhou, T.; Xing, L.; Xu, K.; Tong, Y.; Xie, H.; Zhang, L.; Yan, W.; Chu, W.; Wu, C.; Xie, Y., Atomically Dispersed Iron-Nitrogen Species as Electrocatalysts for Bifunctional Oxygen Evolution and Reduction Reactions. Angew. Chem., Int. Ed. 2017, 56, 610-614.

28. Konkena, B.; Masa, J.; Botz, A. J. R.; Sinev, I.; Xia, W.; Koßmann, J.; Drautz, R.; Muhler, M.; Schuhmann, W., Metallic NiPS3@NiOOH Core-Shell Heterostructures as Highly Efficient and Stable Electrocatalyst for the Oxygen Evolution Reaction. ACS Catal. 2017, 7, 229-237.

29. Luo, W.-B.; Chou, S.-L.; Wang, J.-Z.; Zhai, Y.-C.; Liu, H.-K., A Metal-Free, FreeStanding, Macroporous Graphene@g-C3N4 Composite Air Electrode for High-Energy Lithium Oxygen Batteries. Small 2015, 11, 2817-2824.

30. Xu, K.; Ding, H.; Lv, H.; Tao, S.; Chen, P.; Wu, X.; Chu, W.; Wu, C.; Xie, Y., Understanding Structure-Dependent Catalytic Performance of Nickel Selenides for Electrochemical Water Oxidation. ACS Catal. 2017, 7, 310-315.

31. Chen, G.-F.; Ma, T. Y.; Liu, Z.-Q.; Li, N.; Su, Y.-Z.; Davey, K.; Qiao, S.-Z., Efficient and Stable Bifunctional Electrocatalysts Ni/NixMy $(\mathrm{M}=\mathrm{P}, \mathrm{S})$ for Overall Water Splitting. Adv. Funct. Mater. 2016, 26, 3314-3323.

32. Yu, F.; Zhou, H.; Zhu, Z.; Sun, J.; He, R.; Bao, J.; Chen, S.; Ren, Z., Three-Dimensional Nanoporous Iron Nitride Film as an Efficient Electrocatalyst for Water Oxidation. ACS Catal. 2017, 7, 2052-2057.

33. Zhang, B.; Xiao, C.; Xie, S.; Liang, J.; Chen, X.; Tang, Y., Iron-Nickel Nitride Nanostructures in Situ Grown on Surface-Redox-Etching Nickel Foam: Efficient and Ultrasustainable Electrocatalysts for Overall Water Splitting. Chem. Mater. 2016, 28, 6934-6941.

34. Yu, J.; Li, Q.; Li, Y.; Xu, C.-Y.; Zhen, L.; Dravid, V. P.; Wu, J., Ternary Metal Phosphide with Triple-Layered Structure as a Low-Cost and Efficient Electrocatalyst for Bifunctional Water Splitting. Adv. Funct. Mater. 2016, 26, 7644-7651.

35. Chen, J. G.; Jones, C. W.; Linic, S.; Stamenkovic, V. R., Best Practices in Pursuit of Topics in Heterogeneous Electrocatalysis. ACS Catal. 2017, 7, 6392-6393.

36. Lopes, P. P.; Strmcnik, D.; Tripkovic, D.; Connell, J. G.; Stamenkovic, V.; Markovic, N. M., Relationships between Atomic Level Surface Structure and Stability/Activity of Platinum Surface Atoms in Aqueous Environments. ACS Catal. 2016, 6, 2536-2544.

37. Yang, L.; Lv, Y. L.; Cao, D. P., Co,N-codoped nanotube/graphene 1D/2D heterostructure for efficient oxygen reduction and hydrogen evolution reactions. J. Mater. Chem. A 2018, 6, 39263932.

38. Gao, M. Y.; Zeng, J. R.; Zhang, Q. B.; Yang, C.; Li, X. T.; Hua, Y. X.; Xu, C. Y., Scalable one-step electrochemical deposition of nanoporous amorphous S-doped $\mathrm{NiFe} 2 \mathrm{O} 4 / \mathrm{Ni3Fe}$ composite films as highly efficient electrocatalysts for oxygen evolution with ultrahigh stability. J. Mater. Chem. A 2018, 6, 1551-1560.

39. Xu, K.; Chen, P.; Li, X.; Tong, Y.; Ding, H.; Wu, X.; Chu, W.; Peng, Z.; Wu, C.; Xie, Y., Metallic Nickel Nitride Nanosheets Realizing Enhanced Electrochemical Water Oxidation. J. Am. Chem. Soc. 2015, 137, 4119-4125. 
40. Li, S. W.; Wang, Y. C.; Peng, S. J.; Zhang, L. J.; Al-Enizi, A. M.; Zhang, H.; Sun, X. H.; Zheng, G. F., Co-Ni-Based Nanotubes/Nanosheets as Efficient Water Splitting Electrocatalysts. Adv. Energy Mater. 2016, 6, 1501661.

41. Yang, Y.; Fei, H.; Ruan, G.; Li, Y.; Tour, J. M., Vertically Aligned $\mathrm{WS}_{2}$ Nanosheets for Water Splitting. Adv. Funct. Mater. 2015, 25, 6199-6204.

42. Gao, D. Q.; Zhang, J. Y.; Wang, T. T.; Xiao, W.; Tao, K.; Xue, D. S.; Ding, J., Metallic Ni3N nanosheets with exposed active surface sites for efficient hydrogen evolution. J. Mater. Chem. A 2016, 4, 17363-17369.

43. Jin, S., Are Metal Chalcogenides, Nitrides, and Phosphides Oxygen Evolution Catalysts or Bifunctional Catalysts? ACS Energy Lett. 2017, 2, 1937-1938.

44. Long, X.; Li, G.; Wang, Z.; Zhu, H.; Zhang, T.; Xiao, S.; Guo, W.; Yang, S., Metallic IronNickel Sulfide Ultrathin Nanosheets As a Highly Active Electrocatalyst for Hydrogen Evolution Reaction in Acidic Media. J. Am. Chem. Soc. 2015, 137, 11900-11903.

45. Li, R.; Hu, Z.; Shao, X.; Cheng, P.; Li, S.; Yu, W.; Lin, W.; Yuan, D., Large Scale Synthesis of NiCo Layered Double Hydroxides for Superior Asymmetric Electrochemical Capacitor. Sci. Rep. 2016, 6, 18737.

46. Song, F.; Hu, X., Ultrathin Cobalt-Manganese Layered Double Hydroxide Is an Efficient Oxygen Evolution Catalyst. J. Am. Chem. Soc. 2014, 136, 16481-16484.

47. Lopes, P. P.; Tripkovic, D.; Martins, P. F. B. D.; Strmcnik, D.; Ticianelli, E. A.; Stamenkovic, V. R.; Markovic, N. M., Dynamics of electrochemical Pt dissolution at atomic and molecular levels. J. Electroanal. Chem. 2018, 819, 123-129.

48. Wang, H.; Xu, S.; Tsai, C.; Li, Y.; Liu, C.; Zhao, J.; Liu, Y.; Yuan, H.; Abild-Pedersen, F.; Prinz, F. B.; Nørskov, J. K.; Cui, Y., Direct and continuous strain control of catalysts with tunable battery electrode materials. Science 2016, 354, 1031-1036.

49. Luo, M. C.; Guo, S. J., Strain-controlled electrocatalysis on multimetallic nanomaterials. Nat. Rev. Mater. 2017, 2, 17059.

50. Zhang, D.; Sun, W.; Zhang, Y.; Dou, Y.; Jiang, Y.; Dou, S. X., Engineering Hierarchical Hollow Nickel Sulfide Spheres for High-Performance Sodium Storage. Adv. Funct. Mater. 2016, 26, 7479-7485.

51. Pham, T. V.; Guo, H. P.; Luo, W. B.; Chou, S. L.; Wang, J. Z.; Liu, H. K., Carbon- and binder-free 3D porous perovskite oxide air electrode for rechargeable lithium-oxygen batteries. $J$. Mater. Chem. A 2017, 5, 5283-5289.

52. Liu, W.-M.; Gao, T.-T.; Yang, Y.; Sun, Q.; Fu, Z.-W., A hierarchical three-dimensional $\mathrm{NiCo} 2 \mathrm{O} 4$ nanowire array/carbon cloth as an air electrode for nonaqueous Li-air batteries. Phys. Chem. Chem. Phys. 2013, 15, 15806-15810.

53. Luo, W.-B.; Pham, T. V.; Guo, H.-P.; Liu, H.-K.; Dou, S.-X., Three-Dimensional Array of TiN@Pt ${ }_{3} \mathrm{Cu}$ Nanowires as an Efficient Porous Electrode for the Lithium-Oxygen Battery. ACS Nano 2017, 11, 1747-1754.

54. $\quad$ Gong, M.; Li, Y.; Wang, H.; Liang, Y.; Wu, J. Z.; Zhou, J.; Wang, J.; Regier, T.; Wei, F.; Dai, H., An Advanced Ni-Fe Layered Double Hydroxide Electrocatalyst for Water Oxidation. $J$. Am. Chem. Soc. 2013, 135, 8452-8455.

55. Song, F.; Hu, X., Exfoliation of layered double hydroxides for enhanced oxygen evolution catalysis. Nat Commun 2014, 5, 4477.

56. Dou, Y.; Zhang, L.; Xu, J.; He, C. T.; Xu, X.; Sun, Z.; Liao, T.; Nagy, B.; Liu, P.; Dou, S. X., Manipulating the Architecture of Atomically Thin Transition Metal (Hydr)oxides for Enhanced Oxygen Evolution Catalysis. ACS Nano 2018, 12, 1878-1886. 
57. McCrory, C. C. L.; Jung, S.; Peters, J. C.; Jaramillo, T. F., Benchmarking Heterogeneous Electrocatalysts for the Oxygen Evolution Reaction. J. Am. Chem. Soc. 2013, 135, 16977-16987. 58. Konkena, B.; Puring, K. J.; Sinev, I.; Piontek, S.; Khavryuchenko, O.; Durholt, J. P.; Schmid, R.; Tuysuz, H.; Muhler, M.; Schuhmann, W.; Apfel, U. P., Pentlandite rocks as sustainable and stable efficient electrocatalysts for hydrogen generation. Nat. Commun. 2016, 7 , 12269. 
TOC:

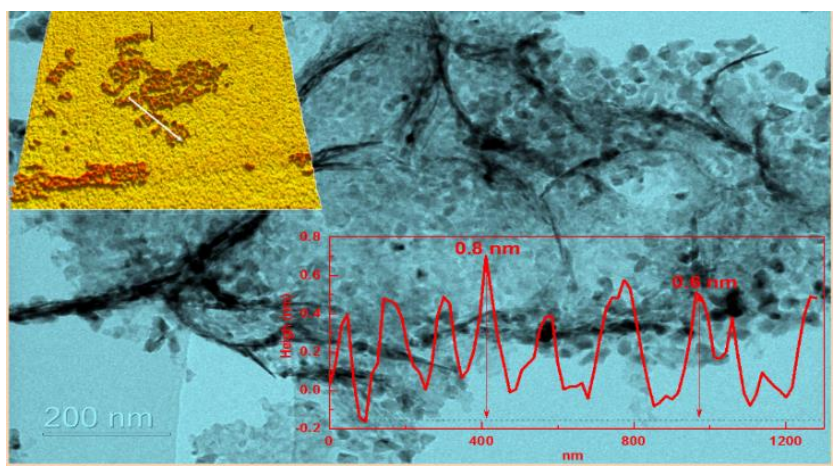

